Published in final edited form as:

Nat Immunol. 2016 May ; 17(5): 565-573. doi:10.1038/ni.3419.

\title{
Late stages of $\mathrm{T}$ cell maturation in the thymus involve NF- $\mathrm{xB}$ and tonic type I interferon signaling
}

\author{
Yan Xing, Xiaodan Wang, Stephen C. Jameson, and Kristin A. Hogquist \\ The Center for Immunology, Department of Laboratory Medicine \& Pathology, University of \\ Minnesota, Minneapolis, Minnesota, USA.
}

\begin{abstract}
Positive selection occurs in the thymic cortex, but critical maturation events occur later in the medulla. We defined the precise stage at which $\mathrm{T}$ cells acquire competence to proliferate and emigrate. Transcriptome analysis of late gene changes suggested roles for NF- $\mathrm{kB}$ and interferon (IFN) signaling. Mice lacking the IKK kinase TAK1 underwent normal positive selection, but exhibited a specific block in functional maturation. NF- $\kappa \mathrm{B}$ signaling provided protection from tumor necrosis factor (TNF) mediated death, and was required for proliferation and emigration. The interferon signature was independent of NF- $\kappa \mathrm{B}$, however IFN-aR-deficient thymocytes showed reduced STAT1 expression and phenotypic abnormality, but were competent to proliferate. Thus, both NF- $\kappa$ B and tonic IFN signals are involved in the final maturation of thymocytes into naïve $\mathrm{T}$ cells.
\end{abstract}

\section{Keywords}

T-cell/thymocytes; functional maturation; NF- $\kappa \mathrm{B}$; interferon/IFN; signaling; TNF receptor superfamily

\section{Introduction}

T cell development occurs in the thymus, which provides a unique microenvironment and presents self-peptide-MHC molecule (pMHC) ligands for T cell receptors (TCRs). In the cortex of the thymus, low affinity TCR interactions initiate positive selection signals in CD4 and CD8 double-positive (DP) immature thymocytes, which supports survival and differentiation to CD4 or CD8 single-positive (SP) thymocytes. Positively selected cells

\footnotetext{
Users may view, print, copy, and download text and data-mine the content in such documents, for the purposes of academic research, subject always to the full Conditions of use:http://www.nature.com/authors/editorial_policies/license.html\#terms

Correspondence should be addressed to K.A.H. (; Email: hogqu001@umn.edu).

Author contributions

Y.X. designed and performed experiments, analyzed data, and wrote the manuscript; X.W performed experiments and analyzed data; S.C.J. provided reagents, animals and input for the preparation of the manuscript; K.A.H. directed the research, analyzed data and wrote the manuscript.

Accession codes Gene Expression Ominbus: GSE74078.

Competing financial interests

The authors declare no competing financial interests.
} 
move to the medullary region, and after several days emigrate to the periphery. The term "positive selection" is sometimes used to describe the entire process. But in thinking about molecular mechanisms, it is helpful to break this down into kinetically distinct processes, such as survival, allelic exclusion, lineage commitment and functional maturation.

Cortical DP thymocytes require interaction of the surface TCR with selecting pMHC to induce survival. Expression of CD69, TCR and Bcl-2 is rapidly upregulated in this population, which also undergo changes in expression of many other genes ${ }^{1,2}$. Genetic deficiency in TCR, MHC, CD4 or CD8 coreceptors or molecules in the TCR signaling pathway blocks this process ${ }^{2}$. Recombination-activating genes (RAG) are rapidly repressed at this stage, facilitating allelic exclusion. CCR7 upregulation occurs somewhat later and facilitates migration of progenitor cells from the cortex to the medulla ${ }^{3}$. Lineage commitment occurs concurrently and involves downregulation of the inappropriate coreceptor gene, and the initiation of genetic remodeling that will ultimately determine if the cell has helper or killer potential. Genetic deficiency of key transcription factors can block CD4 or CD8 commitment ${ }^{4,5}$. Although lineage commitment is mechanistically independent of migration to the medulla, these processes are roughly concurrent. Thus, SP thymocytes reside predominantly in the medulla, however not all SP thymocytes are equivalent.

Previously, CD24 ${ }^{\text {hi }} \mathrm{Q} 2{ }^{\text {lo }}$ SP thymocytes were defined as "semi-mature" and where shown to be susceptible to apoptosis when triggered through the $\mathrm{TCR}^{6}$. In contrast, mature SP thymocyte and thymic emigrants proliferate when triggered through the $\mathrm{TCR}^{6,7}$. Over the years, studies have shown a number of other cell surface proteins, including CD69 and various cytokine and chemokine receptors, change substantially during maturation ${ }^{8,9}$. However, the molecular mechanisms controlling SP thymocyte maturation are unclear.

Here, we defined steps of SP thymocyte maturation, through which SP thymocytes are equipped with mature functions, such as proliferation competency, emigration competency and cytokine licensing. By comprehensive microarray analysis, quantitative real-time PCR (qPCR) and flow cytometric analysis using combinations of several gene-deficient and transgenic mouse models, we found that SP thymocytes receive both tumor necrosis factor (TNF) and type I interferon signals in the thymus, and only TNF-resistant mature thymocytes survive and become emigration competent and licensed to produce cytokines.

\section{Results}

\section{Three SP stages defined by function}

In this study, we sought to determine the ideal flow cytometric markers that define SP thymocyte stages by function. The ordered development of SP thymocytes has previously been characterized by expression of cell surface makers (CD24, CD69, CD62L, Qa2) ${ }^{6},{ }^{10}$, or a carbohydrate epitope $6 \mathrm{C} 10$ on the Thy-1 glycoprotein recognized by a monoclonal antibody (mAb) SM6C10 (ref. 9), or chemokine receptors CCR7 and CCR9 (ref. 11). However, these markers have not been well correlated with functional maturation. We performed a comprehensive flow cytometric analysis employing Rag2-green fluorescent protein $\left(\operatorname{Rag} 2^{\mathrm{GFP}}\right) \mathrm{BAC}$ transgenic mice, wherein GFP expression acts as a "molecular timer" for post-positive selection differentiation events ${ }^{10,12}$ and allows exclusion of re- 
circulating mature $\mathrm{T}$ cells. To focus our analysis on conventional a $\beta \mathrm{T}$ cells, we used a "dump strategy" to exclude $\gamma \delta$ T cells, invariant natural killer T cells (INKT), and regulatory $\mathrm{T}\left(\mathrm{T}_{\text {reg }}\right.$ ) cells (Supplementary Fig. 1a). We found that the combination of CD69 and MHC class I (MHCI) staining precisely defines SP thymocyte stages by function, and can be used on both CD4 and CD8 lineage cells. Positively selected medullary thymocytes $\left(\mathrm{TCR} \beta^{+} \mathrm{CCR} 7^{+}\right)$clearly have three populations based on CD69 and MHCI expression, including $\mathrm{CD}^{+} 9^{+} \mathrm{MHCI}^{-}, \mathrm{CD} 9^{+} \mathrm{MHCI}^{+}$and $\mathrm{CD}^{-} 9^{-} \mathrm{MHCI}^{+}$(Fig. 1a) ${ }^{13}$. GFP expression was gradually decreased in this order, indicating that $\mathrm{CD} 69^{+} \mathrm{MHCI}^{-}$thymocytes precede $\mathrm{CD} 9^{+} \mathrm{MHCI}^{+}$cells, and that $\mathrm{CD}^{-} 9^{-} \mathrm{MHCI}^{+}$cells are the most mature population. Note that after the initiation of positive selection, CD4SP cells quickly repress CD8 expression, whereas CD8SP cells extinguish CD4 more slowly ${ }^{14}$. Thus MHCI-restricted medullary thymocytes are in the DP gate at the $\mathrm{CD}^{+} 9^{+} \mathrm{MHCI}^{-}$stage, and do not complete downregulation of $\mathrm{CD} 4$ until the $\mathrm{CD}^{-} 9^{-} \mathrm{MHCI}^{+}$stage (Fig. 1a). This gating strategy was confirmed in MHC class II-deficient mice, in which only $\mathrm{CD} 8^{+} \mathrm{T}$ cells can be positively selected in the thymus (Supplementary Fig. 1b).

To assess proliferation competence, we sorted the three populations, labeled using CellTrace Violet (CTV), and stimulated them in vitro with anti-CD3 plus anti-CD28. $\mathrm{CD}^{+} 9^{+} \mathrm{MHCI}^{-}$ cells did not proliferate, while $\mathrm{CD}^{+} 9^{+} \mathrm{MHCI}^{+}$and $\mathrm{CD}^{-} 9^{-} \mathrm{MHCI}^{+}$thymocytes did, suggesting that MHC class I upregulation most precisely defines the boundary between proliferationincompetent and -competent cells (Fig. 1b). Thus, we designated $\mathrm{CD}^{+} 9^{+} \mathrm{MHCI}^{-}$population as semi-mature (SM), and $\mathrm{CD}^{+} 9^{+} \mathrm{MHCI}^{+}$and $\mathrm{CD}^{-} 9^{-} \mathrm{MHC1}^{+}$populations as mature 1 (M1) and mature 2 (M2), respectively. To assess emigration and trafficking competence, we examined expression of sphingosine 1 phosphate receptor 1 (S1PR1) ${ }^{15}$, L-selectin $(\mathrm{CD} 62 \mathrm{~L})^{16}$ and the transcription factor Kruppel-like factor 2 (KLF2), which is required for expression of S1PR1 and CD62L in thymocytes ${ }^{15,16,17}$. S1PR1 and CD62L were highly expressed on M2 cells, but not on SM and M1 cells (Fig. 1c). Likewise, KLF2 was highly expressed only on M2 cells (Supplementary Fig. 1c). Thus, amongst proliferation competent M1 and M2 thymocytes, only the most mature M2 cells are competent to emigrate. Finally, we assessed at which stage SP thymocytes became licensed to produce the cytokine $\mathrm{TNF}^{18}$. Only the M2 subset had a substantial population of TNF-producing cells following stimulation via CD3 and CD28 (Fig. 1d), and this fraction continued to increase in recent thymic emigrants (data not shown), consistent with previous reports ${ }^{18}$.

Previously reported staining combinations ${ }^{6,9}$, which included two populations defined as $\mathrm{CD} 24^{\mathrm{hi}} \mathrm{Qa} 2{ }^{\mathrm{lo}}$ and $\mathrm{CD} 24^{\mathrm{lo}} \mathrm{Q} 22^{\mathrm{hi}}$ or four populations designated SP1 to SP4 by the combination of CD69, Qa2 and the anti-Thy1 mAb SM6C10, did not precisely distinguish between proliferation-incompetent (SM) and -competent (M1) cells, although nicely distinguished emigration-competent cells from others (Supplementary Fig. 1d). The combination of chemokine receptors CCR7 and CCR9 together with CD69 on CD4SP thymocytes ${ }^{11}$ somewhat distinguished proliferation-incompentent (CCR9hi) and -competent $\left(\mathrm{CCR} 9^{\text {int/lo }}\right)$ CD4SP cells (Supplementary Fig. 1d, left), but this staining panel did not separate CD8SP thymocytes very well (Supplementary Fig. 1d, right), as mature CD8SP cells expressed abundant CCR9. Thus, the expression of CD69 and MHCI are the most effective measures of the late stages of $\mathrm{T}$ cell maturation. 


\section{Transcriptome analysis implicates NF- $\mathrm{BB}$ and IFN}

DP thymocytes have a substantially different gene expression profile compared to T cells ${ }^{19}$, consistent with the apoptosis susceptibility of the former and proliferation competence of the later. Yet our data and previous results suggest that the apoptosis to proliferation change occurs at the SM to M stage in the medulla, which we estimate is at least 24 hours after the initiation of positive selection signaling ${ }^{6,20}$. Thus we hypothesized that the unique gene changes that occur late in the process might be most relevant to understanding the competence transition. To characterize these gene changes, we mined microarray data from thymocytes that were isolated using the previously defined Qa2 and CD69 markers to designate four stages (Fig. 2). CD69- TCR $\beta^{-}$pre-selection DP (pre-DP) and CD69 ${ }^{+}$TCR $\beta^{+}$ post-selection DP (post-DP) cells were sorted from the thymus of $\beta 2 \mathrm{~m}$-deficient $\left(B 2 \mathrm{~m}^{-/-}\right)$ mice, in which only MHC II-restricted $\mathrm{CD}^{+}{ }^{+} \mathrm{T}$ cells undergo positive selection. Qa2 ${ }^{-} \mathrm{CD} 69^{+}$ (SM/M1) and $\mathrm{Qa}^{+}{ }^{+} \mathrm{CD} 69^{-}(\mathrm{M} 2) \mathrm{CD} 4 \mathrm{SP}$ cells were sorted from thymocytes of Rag2 ${ }^{\mathrm{GFP}}$ mice with a "dump" channel that included NK1.1, CD25 and GL3. The "dump" and Rag2GFP gates allowed the exclusion of $I$ NKT cells, $T_{\text {reg }}$ and $\gamma \delta \mathrm{T}$ cells, and recirculating mature $\mathrm{T}$ cells, which can include up to 15\% of CD4SP cells (Supplementary Fig. 2a). Through analyzing the microarray data, we identified significantly changed genes and categorized them upon their expression kinetic patterns (Fig. 2). By far the largest number of gene expression changes, 2060 up- or down-regulated genes, were initiated during the cortical positive selection step from pre-DP to post-DP (Supplementary Fig. 2b). Some of these changes occurred only early (group A), some continued to change at later stages (group B) and a few were transient (group C). Interestingly, a substantial number of gene expression changes occurred between the post-DP to SM stage (1005 genes, groups D \& E), whereas only a small number of genes altered their expression at the very end of medullary maturation (269 genes, group F), including a number of genes whose changes were initiated earlier, but were reversed. Using these expression pattern groups, we defined sets of genes that change early or late during selection (Fig. 2).

To understand what upstream pathways and molecular factors might be acting at early and late stages we utilized Gene Set Enrichment Analysis (GSEA) tools. Certain gene sets that share a conserved cis-regulatory motif in the promoters and 3'UTRs among genes (this is referred to as the "C3 motif" in GSEA) were enriched at distinct stages (Table 1). A number of transcription factor binding sites were enriched among the promoters of genes induced or repressed during positive selection (pre-DP to post-DP), including those motifs recognized

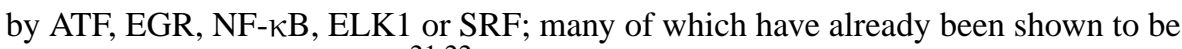
involved in positive selection ${ }^{21}$, 22 . E2F-regulated genes showed a strong negativeenrichment score, indicating down regulation. Among genes that changed at later time points during the post-DP to SM/M1 stage, only E2F, NF- $\kappa \mathrm{B}$, and IRF gene sets were enriched. E2F-regulated genes appear upregulated at this stage, reflecting the transient nature of their repression during positive selection. Among the NF- $\kappa \mathrm{B}$-regulated genes, some changes were initiated earlier, at the pre-DP to post-DP transition, and others initiated later, at the post-DP stage. A strong enrichment for IRF-regulated genes was seen only at the post-DP to SM/M1 stage. The number of gene changes observed at the latest stage of maturation was small (413), and there was no significant positive enrichment of any transcription factor binding sites at this stage (NES scores $\geq 1.6$ or $\leq-1.6$ ). Because this analysis suggested that NF- $\kappa \mathrm{B}$ - 
and IRF-regulated gene changes occur late after positive selection, we focused on their effects in this study.

\section{TAK1 is required for the transition from SM to M1}

Mice deficient in a number of genes in the NF- $\kappa \mathrm{B}$ pathway display near-normal numbers of total thymocytes but few peripheral $\mathrm{T}$ cells ${ }^{23}$, including those encoding TGF- $\beta$-activated kinase 1 (TAK1), IKK2, IKK $\gamma$, RelB, and Ubc13. Among these, we focused on the TAK1 molecule as a central kinase in this pathway (Supplementary Fig. 3a). Consistent with previous studies ${ }^{24},{ }^{25},{ }^{26}$, we found that mice with T cell specific TAK1 deficiency ( $T a k I^{\mathrm{fl} / \mathrm{fl}} \mathrm{Cd} 4^{\mathrm{Cre}}$ ) have a normal number of thymocytes compared with littermate controls, but the proportions and absolute numbers of both CD4 and CD8 SP thymocytes were decreased. We further investigated the stage at which TAK1 deficiency impacts maturation, and found normal numbers of SM cells, but a profound reduction of M1 and M2 cells, 10fold and 100-fold respectively (Fig. 3a,b). This suggests that TAK1 dependent signals are not required for positive selection, per se, but for the ultimate survival and/or maturation of T cells. Mature ${ }_{N}$ NKT, $T_{\text {reg }}$ and intraepithelial lymphocyte precursor (IELp) thymocytes are almost completely absent in $T a k I^{\mathrm{fl} / \mathrm{fl}} C d 4^{\mathrm{Cre}}$ mice as well (Supplementary Fig. 3b). To determine if TAK1 could be a key driver of late gene expression changes during selection, we performed microarray analysis of purified SM CD4SP thymocytes from $T a k \mathrm{fl}^{\mathrm{fl} / \mathrm{fl}} \mathrm{Cd} \mathrm{C}^{\mathrm{Cr}}$ and control mice. 381 genes were up- or down-regulated by TAK1 deficiency. Using a heat map to visual the overall pattern of gene changes, we noted that TAK1-dependent genes were predominantly changed at the late stage of maturation in normal mice, as opposed to early (Fig. 3c). Next we used Ingenuity Pathway Analysis to define potential upstream regulators based on the $P$-value of overlap between our gene lists and those defined by the literature (Supplementary Fig. 4). The upstream regulators defined for early gene expression changes include those encoding TCR, TGF- $\beta$ and Id proteins, among others. In contrast, late gene expression changes overlapped with many interferon and IRF pathways, consistent with enrichment of IRF sites in the promoters at late changed transcripts.

Importantly, the upstream regulators defined for TAK1-dependent genes were highly similar to those of late changed transcripts (regulators highlighted in yellow or green in

Supplementary Fig. 4), suggesting that TAK1 dependent processes are the dominant signals driving gene expression changes late in positive selection.

\section{TNF blockade restored survival but not proliferation}

Because NF- $\kappa$ B activation protects cells from TNF-induced cell death ${ }^{27}$, we addressed if the role of TAK1 signaling in positive selection might primarily be to allow survival at the mature stage or if it is required for differentiation and the acquisition of proliferation competence. We crossed $\operatorname{Tak}^{\mathrm{fl} / \mathrm{fl}} \mathrm{Cd} 4^{\mathrm{Cre}}$ mice to TNF-deficient ( $\operatorname{Tnf}^{{ }^{\prime-}}$ ) mice. In $T a k I^{\mathrm{fl} / \mathrm{fl}} \mathrm{Cd} 4^{\mathrm{Cre}} \mathrm{Tnf}^{1-}$ mice, the number of M1 cells was completely restored to be equivalent to those observed in $\operatorname{Tak} I^{\mathrm{fl} / \mathrm{fl}}$ mice, suggesting that one role for TAK1 signals is to protect from TNF-induced death. However, M2 cells were only partially rescued (Fig. 4a,b), and double-deficient mice were profoundly lymphopenic in the periphery (data not shown). Multiple other TNF receptor family members are upregulated during thymic maturation (Supplementary Fig. 5a,b) and similar to TNFR1, one of these-Death Receptor 3 (DR3) — contains a death domain and cells expressing this receptor might also require NF- $\kappa \mathrm{B}$ 
signals for protection from induced cell death. However, crossing $T a k 1^{\mathrm{fl} / f l} C d 4^{\mathrm{Cre}}$ to mice transgenic for Bcl2 (data not shown) or deficient in Bim $\left(B c 12111^{-1-}\right.$ ) (Supplementary Fig. $\mathbf{5 c}, \mathbf{d})$ yielded a similar phenotype, with low numbers of M2 cells and peripheral lymphopenia. Although TNF deficiency restored mature cell numbers, those cells were unable to proliferate in response to anti-CD3 plus anti-CD28 (Fig. 4c). These data suggest that TAK1 signals may be required for differentiation in addition to cell survival.

\section{IKK activity restored proliferation but not licensing}

TAK1 signals result in both NF- $\kappa$ B and MAP kinase activation ${ }^{28}$. To determine which TAK1-dependent functions involved NF- $\kappa \mathrm{B}$, we used a constitutively active $I k b k b$ (also known as IKK2) transgene to restore NF- $\mathrm{BB}$ activation in TAK1-deficient mice. We employed a Cre-directed IKK2-constitutively active transgene (hereafter called IKKCA) crossed to the $T a k I^{\mathrm{fl} / \mathrm{fl} l} C d 4^{\mathrm{Cre}}$ mice (use of $C d 4^{\mathrm{Cre}}$ avoids the documented effects of IKKCA on the DN thymocytes ${ }^{29}$ ). Both the proportions and the cell numbers of mature SP thymocytes in Tak ${ }^{f l / f l} C d 4^{\mathrm{Cre}} I K K C A$ mice were increased compared to $T a k I^{\mathrm{fl} / \mathrm{fl} l} C d 4^{\mathrm{Cre}}$ mice and showed no significant difference from those in $C d 4^{\mathrm{Cre}} I K K C A$ control mice (Fig. 5a,b). Notably, the proportion and the number of M1 and M2 subsets were rescued to levels similar to $C d 4^{\mathrm{Cre}} I K K C A$ control mice. Furthermore, M1 and M2 cells from the thymi of $T a k I^{\mathrm{fl} / \mathrm{fl}} C d 4^{\mathrm{Cre}} I K K C A$ mice proliferated in response to anti-CD3, as did control Tak $f^{\mathrm{fl} / \mathrm{fl}}$ mice (Fig. 5c), albeit to a slightly lesser degree. These results indicate that NF- $\kappa B$ activation driven by constitutive-active IKK restored phenotypic maturation and proliferation competence in TAK1-deficient SP thymocytes.

Finally, we assessed TNF production using the IKKCA restored TAK1-deficient SP thymoyctes. In contrast to $15-20 \%$ of TNF-producing cells among the M2 population from Tak $I^{\mathrm{fl} / \mathrm{fl}}$ mice, only $1-2 \%$ of the M2 cells from Tak $I^{\mathrm{fl} / \mathrm{fl}} C d 4^{\mathrm{Cre}} I K K C A$ mice produced TNF after the stimuli of $\mathrm{CD} 3$ and $\mathrm{CD} 28$ (Fig. 5d). Furthermore, Tak $I^{\mathrm{fl} / \mathrm{fl}} C d 4^{\mathrm{Cre}} I K K C A$ mice have very few $\mathrm{CD}^{+}$and $\mathrm{CD} 8^{+} \mathrm{T}$ cells in the spleen, similar to $\mathrm{Tak} \mathrm{I}^{\mathrm{fl} / \mathrm{fl}} \mathrm{Cd} 4^{C r e}$ mice (Fig. 5e,f). M2 cells from $T a k 1^{\mathrm{fl} / \mathrm{fl}} C d 4^{\mathrm{Cre}} I K K C A$ mice express normal amounts of S1PR1, arguing against a problem with the emigration competency of M2 cells (Fig. 5g), raising the possibility that those cells cannot survive in the periphery. Thus, although IKKCA restored several aspects of maturation in TAK1-deficient SP thymocytes, it did not restore cytokine production competence or establishment of $\mathrm{T}$ cell populations in the periphery.

\section{TAK1 facilitates IFN signaling independently of NF- $K B$}

To understand which TAK1-dependent gene expression changes are dependent on NF- $\kappa \mathrm{B}$ activity and which are independent, we measured the expression of 20 TAK1-dependent genes that were identified by microarray and confirmed by qPCR (Fig. 3c,d). Thus we sorted SM and M2 cells from Tak $I^{\mathrm{fl} / \mathrm{fl}}, T a k f^{\mathrm{fl} / \mathrm{fl}} C d 4^{\mathrm{Cre}}$ and Tak $I^{\mathrm{fl} / \mathrm{fl}} C d 4^{\mathrm{Cre}} I K K C A$ mice and measured gene expression by qPCR. Expression of about half of these genes was restored by the IKKCA transgene ( 9 genes Fig. 6a, left), and half were not (11 genes Fig. 6a, right). Interestingly, many of the later genes are interferon-regulated genes, suggesting that TAK1 regulates IFN signaling in a pathway that cannot be substituted by NF- $\kappa \mathrm{B}$ activity. We noticed that expression of Stat 1 mRNA itself was not restored by IKKCA, and STAT1 is an essential mediator of interferon signaling. Thus, we measured intracellular STAT1 protein. 
STAT1 expression increased from the SM to M1 stage, and there was less total STAT1 protein in M1 and M2 SP thymocytes from Tak $f^{\mathrm{fl} / f l} C d 4^{\mathrm{Cre}} I K K C A$ mice compared to control mice (Fig. 6b), suggesting they may have reduced responsiveness to interferons.

Recent studies have shown that interferon- $\beta$ (IFN- $\beta$ ) is constitutively expressed in thymic medullary epithelial cells from naïve mice 30,31 . Considering that an IFN-regulated gene signature was apparent in medullary thymocytes from our microarray analysis, we sought to test the hypothesis that maturing thymocytes may respond to constitutively produced interferon in the thymus. To address this, we examined type I interferon receptor-deficient $\left(\right.$ Ifnar $1^{1^{-}}$) mice. Indeed, sorted mature thymocytes from Ifnar $1^{-1-}$ mice showed reduced expression of a number of genes (Fig. 6c). The most strongly affected genes were all NF$\kappa \mathrm{B}$-independent IFN-regulated genes from Fig. 6a, demonstrating that medullary thymocytes normally respond to constitutively produced interferon. Among the genes with reduced expression were Stat 1 and Irf7, previously shown to be targets of constitutive type I IFN signaling, and essential for "priming" cells for cytokine responsiveness ${ }^{32,33}$. Thus, next we closely examined the phenotype and function of SP thymocytes from type I IFN receptor-deficient (Ifnar ${ }^{-1-}$ ) mice. SM, M1 and M2 CD4 SP thymocyte numbers were similar between Ifnar ${ }^{1-}$ and control mice (Fig. 6d). Many other maturation markers were also expressed normally (data not shown). However, CCR7 expression was slightly increased on Ifnar $1^{-1-}$ CD8SP thymocytes, and Qa2 expression was radically decreased on M2 CD4SP and CD8SP cells (Fig. 6e). The response to interferon deficiency is cell intrinsic, as Ifnar $1^{-/}$progenitors injected intrathymically into wild-type recipients still showed severe Qa2 loss (data not shown). We did not detect functional deficiency in mature thymocytes from Ifnar $1^{-1-}$ mice in terms of proliferation or licensing (Supplementary Fig. 6). However, Ifnar ${ }^{-1-}$ cells make deficient responses to IL-6, IFN- $\gamma$, and M-CSF, consistent with their reduced expression of STAT1 and IRF $7{ }^{34}$. Thus, thymocytes respond to interferon constitutively during development, and this may prime their responsiveness to other cytokines.

\section{Discussion}

Our data provide a precise examination of gene expression changes that occur after positive selection, and how they relate to function. While several gating strategies have been proposed to demarcate functionally relevant stages ${ }^{6,9},{ }^{11}$, our data suggest that MHCI upregulation most precisely marks the stage at which cells acquire the competence to proliferate. Other strategies fail in this regard, although they are accurate at marking the stage at which cells become emigration competent. The only other cell surface protein whose change correlates with the acquisition of cell division competence is GITR. Qa2 is commonly used to mark the most mature thymocytes, but we found that Qa2 was strongly dependent on IFN-I signaling in SP and not associated with maturation per se. This is consistent with the observation that Qa2 is AIRE dependent ${ }^{9},{ }^{35}$, yet $\mathrm{T}$ cells in AIRE deficient mice are not thought to have major maturational defects.

These observations about Qa2 expression suggest that IFN $\beta$ is produced by mTEC in the steady state. Some independent evidence supports this notion ${ }^{30,31}$, yet further investigation is needed given that constitutive IFN $\beta$ production can also be driven by the 
microbiota $^{36,37,38}$ or DNA damage ${ }^{39,40}$. Regardless of the source, an important question is how the exposure to type I IFN during development changes the functional properties of T cells. There is a growing appreciation that constitutive or tonic IFN signaling maintains homeostasis and primes cytokine responsiveness in other hematopoetic cell types ${ }^{34}$. Recent analysis of Ifnar ${ }^{-/-}$mixed bone marrow chimeras suggests an important role for constitutive IFN signals in T cell development and Treg cell homeostasis ${ }^{41}$, so further studies of how IFN alters T cell gene expression and function are warranted.

The main finding of our study was that NF- $\kappa \mathrm{B}$ signaling is critical for late maturation processes - both for survival at the SP stage and for functional maturation. Regarding survival, it is well established that TNFR signals can trigger both NF- $\kappa$ B activation and death, through signaling pathways that have been referred to as complex I and $\mathrm{II}^{42}$. Complex I signaling results in NF- $\kappa \mathrm{B}$ activation and protection against complex II mediated death. Our results establish that TNF is present in the thymic environment and can mediate cell death, since TNF deficiency was able to rescue mature cell numbers in TAK1 deficient mice. This finding is consistent with the phenotype of mice deficient in c-FLIP ${ }^{43}$, which interferes with apoptotic signaling downstream of death receptors. Although TNF was shown to be a source of the death signal, rescue was not complete with TNF deficiency. Thus it is possible that DR3, another death domain containing TNFR family member expressed in medullary thymocytes, contributes as well.

Our data provide definitive evidence that $N F-\kappa B$ signals are required for late maturation. This is consistent with a number of reports in the literature where positive selection was normal, but animals showed peripheral T cell lymphopenia (e.g. IKK $\gamma$, IKK1/2, Ubc13). Subtle differences in the phenotype may reflect differences in the rate of protein loss post Cre mediated deletion in the different models (for example with IKK $\gamma$ ) and/or redundancies with related components of the pathway (for example with IKK1 and 2). Numerous receptors can activate the TAK $1 / \mathrm{NF}-\kappa \mathrm{B}$ pathway. The TCR is an obvious candidate, since $\mathrm{NF}-\kappa \mathrm{B}$ regulated genes were enriched in genes that changed both at positive selection and into the SM stage. However, the TCR activates TAK1/NF- $\kappa$ B through a Carma1/Bcl10/ Malt1 signalosome, and mice deficient in those components do not exhibit this phenotype, although they do lack mature Treg cells ${ }^{44,45,46}$. We also feel the TCR is unlikely to be the sole source of TAK1 activation in conventional T cells because the interaction of the TCR with MHC Class II is required for survival from Post-DP to SM, but it is not required for survival or maturation from SM to mature stages (our data not shown and 8), although this is controversial $^{47}$. Thus, there is a distinction between conventional $\mathrm{T}$ cells and Treg cells, where both require NF- $\kappa \mathrm{B}$ activation through TAK1, but conventional $\mathrm{T}$ cells seem to receive sufficient $\mathrm{NF}-\kappa \mathrm{B}$ stimulus without the TCR. TGF $\beta \mathrm{R}$ signaling may provide TAK1 activation in medullary thymocytes. However, TGF $\beta$ R was not identified as a potential upstream regulator in our analysis of either late changed genes or TAK 1 dependent genes. Furthermore, mice with TGF $\beta$ R deficiency in T cells do not show a maturation problem per se, although again they have impaired development of Treg and iNKT cells ${ }^{48,49}$.

We favor the hypothesis that multiple TNFR family members can provide TAK1 signals to promote survival and maturation in developing thymocytes. These include TNFR1 and TNFR2, which bind to TNF. TNFR1 is expressed constitutively in thymocytes, while 
TNFR2 increases notably from the DP to SP stage. Mice with TNF deficiency alone do not have a maturation defect, thus we propose that OX40, GITR, CD27, and DR3 provide redundant signals, as these receptors are either constitutively expressed (CD27) or are induced by positive selection (OX40, GITR, and DR3). The ligands for some of these (CD70, OX40L and GITRL) are known to be expressed in the thymus, particularly the thymic medulla ${ }^{50}$. This raises the possibility that thymocytes may need to access the medullary environment to receive signals for maturation. From data available to date, this seems not to be the case. Thymocytes lacking CCR7 fail to localize to the thymic medulla after positive selection and have defects in central tolerance, but mature and emigrate normally ${ }^{25}$. Likewise, mice lacking an organized medullary environment also have defects in central tolerance, but seem to mature normally ${ }^{11}$.

In summary, our data reveal two critical features of $\mathrm{T}$ cell maturation that occur after positive selection, but before cells emigrate from the thymus. Activation of NF- $\kappa \mathrm{B}$ occurs at the SM stage. NF- $\kappa B$ activity is critical to protect cells from complex-II mediated death downstream of TNF-R1, as it is in many cell types. However, in thymocytes NF- $\kappa$ B activity is also critical for maturation processes that allow the cell to mount a proliferative response when stimulated through the antigen receptor. A second critical feature is that thymocytes respond to constitutively produced type I IFN in the medullary environment. This response is dependent on TAK1, but independent of NF- $\kappa \mathrm{B}$. Constitutive type I interferon signaling results in the upregulation of STAT1 and IRF7, and primes T cells to response to inflammatory cytokines.

\section{Methods}

Mice

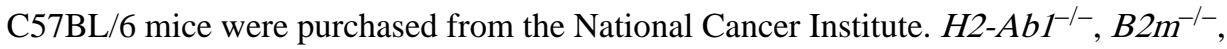
Tak $f^{\mathrm{fl} / \mathrm{fl}}, C d 4^{\mathrm{Cre}}, \mathrm{R} 26-\mathrm{Stop}^{\mathrm{FL}} I k k 2 \mathrm{ca}(I K K C A)$ and $T n f^{/-}$mice were obtained from Jackson Laboratories. Bcl211 $1^{-1-}$ and Ifnar $1^{1^{--}}$mice were kindly provided by A. Strasser (Walter and Eliza Hall Institute, Melbourne, Australia) and M. Mescher (University of Minnesota,

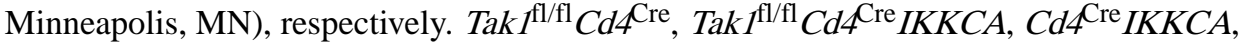
$T a k I^{\mathrm{fl} / \mathrm{fl}} C d 4^{\mathrm{Cre}} \mathrm{Tnf} \mathrm{f}^{/-}$and $\mathrm{Tak} I^{\mathrm{fl} / \mathrm{fl}} \mathrm{Cd} 4^{\mathrm{Cre}} B c l 2111^{-/-}$mice were generated by crossbreeding at the University of Minnesota. Rag $2^{\mathrm{GFP}}$ and $K l f 2^{\mathrm{GFP}}$ mice were described ${ }^{10,51}$. Animals were maintained under specific-pathogen-free conditions at the University of Minnesota. All experimental procedures were approved by the institutional animal care and use committee at the University of Minnesota.

\section{Flow Cytometry, MACS purification and Cell Sorting}

Single-cell suspensions were stained for 20 minutes on ice with the indicated antibodies. Antibodies were purchased from BD Biosciences: CD3 (145-2C11), CD4 (GK1.5), CD8a (53-6.7), CD24/HSA (M1/69), CD25 (PC61), CD27 (LG3A10), CD28 (37.51), CD30 (2SH12-5F-2D), CD40 (3/23), CD44 (IM7), CD62L (MEL-14), CD69 (H1.2F3), CD137/41BB (1AH2), MHCI/H2-Kb (AF6-88.5) and TCRbeta (H57-597). Antibodies were purchased from Biolegend: CD120a/TNFRI (55R-286), CD120b/TNFRII, (TR75-89), CD199/CCR9 (CW-1.2), CD267/TACI (8F10), DR3 (4C12), and Qa2 (695H1-9-9). S1PR1 
antibody (713412) was purchased from Bio-Techne. CD134/OX40 (OX86) antibody was purchased from eBioscience. CD197/CCR7 (4B12, Biolegend) staining was performed for 15 minutes at $37^{\circ} \mathrm{C}$ at $37^{\circ} \mathrm{C}$. Fluorescent $\mathrm{CD} 1 \mathrm{~d}-\mathrm{a}-\mathrm{GalCer}$ tetramers preparation was described $^{51}$. Data were collected using an LSR Fortessa instrument (BD Biosciences) and analyzed using FlowJo (Tree Star). For intracellular Foxp3 (NRRF-30, eBioscience) staining, cells were stained using the eBioscience Foxp3 staining kit and manufacturer's protocol. To isolate CD4SP subsets, we depleted CD8SP and DP thymocytes via negative selection with biotinylated anti-CD8b.2 (53-5.8, BD Biosciences) and StreptAvidin MACS beads (Miltenyi Biotech) by using MACS separation columns (Miltenyi Biotech) prior to cell sorting. For CD8SP subsets, we enriched CD8SP thymocytes via positive selection with biotinylated anti-TCRbeta (H57-597) prior to cell sorting. Cells were sorted on a FACSAria (Becton Dickinson) and results were reliably $>90 \%$ of the target population.

\section{Microarray Analysis}

RNA from sorted cells was extracted using RNeasy Mini kit (Qiagen) with on column DNase step (Qiagen) per the manufacturer's instructions. RNA was then quantified using a Nanodrop 2000/2000c spectrophotometer (Thermo Scientific). RNA (150-300 ng) was used for generating biotinylated cRNA through single-round amplification using the MessageAmpIII RNA Amplification kit following the manufacturer's recommendations (Ambion). A total of $20 \mu \mathrm{g}$ of biotinylated cRNA was fragmented and hybridized to Affymetrix murine 4302.0 gene chips (Affymetrix), and scanned at the Biomedical Genomic Center (University of Minnesota) following standard procedures. Three independent RNA samples were analyzed. The microarray data were analyzed using GeneSpring GX 11 software (Agilent). The normalization was carried out using MAS5 algorithm. Probe sets were filtered by flag values (present/marginal as acceptable flags), and probe sets with $P \leq 0.05$ (unpaired $t$-test) were considered statistical significance, then probe sets showing fold change differences $\geq 2.0$ were considered as differentially expressed. All data have been deposited at GEO (accession code GSE74078).

\section{GSEA and IPA Analysis}

GSEA was performed on microarray data using GSEA software (Broad Institute) per Broad Institute instructions ${ }^{52}, 53$. C 3 transcription factor target gene sets contain genes that share a transcription factor binding site defined in the TRANSFAC (version 7.4, http://www.generegulation.com/) database. Each of these gene sets is annotated by a TRANSFAC record. Pathway analysis was performed using Ingenuity Pathway Analysis (IPA) software (Ingenuity System) according to its instructions.

\section{Quantitative RT-PCR (qPCR)}

An RNeasy mini kit (Qiagen) and SuperScript III First Strand Synthesis SuperMix for qRTPCR (Invitrogen) were used for the isolation of RNA and production of cDNA. FastStart Universal SYBR Green Master (Roche) and an ABI PRISM 7900HT sequence detection system (Applied Bioscience) were used for amplification and detection. Hprt (hypoxanthine guanine phosphoribosyl transferase) was used for normalization of samples. Primers were described in Supplementary Table 1. 


\section{CellTrace Violet Cell Proliferation analysis}

Sorted cells were labeled with CellTrace Violet (CTV) (Molecular Probes) and cultured in complete medium (RPMI-1640 medium containing 5 mM HEPES pH7.5, 2 mM Lglutamine, $50 \mu \mathrm{M}$ 2-mercaptoethanol, $50 \mathrm{U} / \mathrm{ml}$ of penicillin, $50 \mu \mathrm{g} / \mathrm{ml}$ ptreptomycin, 50 $\mu \mathrm{g} / \mathrm{ml}$ gentamicin sulfate and $10 \% \mathrm{FBS})$ in a 96 -well round bottom plate coated with antiCD3 (145-2C11, BD Bioscience; $10 \mu \mathrm{g} / \mathrm{ml}$ ) and anti-CD28 (37.51, BD Bioscience; 20 $\mu \mathrm{g} / \mathrm{ml}$ ) antibodies. After 3 days, cells were analyzed by flow cytometry after staining with Fixable Viability Dye eFluor 780 (eBioscience), which was used to exclude dead cells. The intensity of CTV dye is diluted by half for every cellular division.

\section{TNF production assay}

Total thymocytes were stimulated with plate-bound anti-CD3 plus anti-CD28 in the presence of GolgiPlug (BD Bioscience). $4 \mathrm{~h}$ later, cells were treated with Cytofix/Cytoperm (BD Bioscience) for $30 \mathrm{~min}$ on ice after surface staining, and then stained for intracellular TNF (MP6-XT22, BD Bioscience).

\section{Intracellular staining of STAT1}

We stained freshly isolated thymocytes with surface markers, then treated them using Cytofix/Cytoperm (BD Biosciences) for $30 \mathrm{~min}$ on ice. Intracellular STAT1 was stained with anti-STAT1 rabbit polyclonal antibody (ab92506, Abcam) and subsequently with Alexa Fluor 647-conjugated goat anti-rabbit IgG (Invitrogen). Data were acquired on an LSRFortessa flow cytometer with FACSDiva software and analyzed using FlowJo (Tree Star).

\section{Statistical analysis}

Standard deviation and $P$-values were determined using Prism software (GraphPad Software, Inc.). $P$-values were calculated using a two-tailed unpaired Student's $t$-test with $95 \%$ confidence interval.

\section{Supplementary Material}

Refer to Web version on PubMed Central for supplementary material.

\section{Acknowledgements}

We thank H. Chi (St. Jude Children's Hospital) for providing Rag2 GFP mice; M. Mescher for providing Ifnar ${ }^{-/-}$ mice; A. Strasser (Walter and Eliza Hall Institute, Melbourne, Australia) for providing Bcl211 $1^{-/}-$mice; and K. Hayakawa (Fox Chase Cancer Center) for providing SM6C10 antibody. We thank M.A. Farrar for helpful comments and review of the manuscript. This work was supported by an NIH grants (RO1 AI088209 and PO1 AI35296) to K.A.H.

\section{References}

1. Huang YH, Li D, Winoto A, Robey EA. Distinct transcriptional programs in thymocytes responding to T cell receptor, Notch, and positive selection signals. Proc. Natl. Acad. Sci. USA. 2004;

101:4936-4941. [PubMed: 15044701] 
2. Mick VE, Starr TK, McCaughtry TM, McNeil LK, Hogquist KA. The regulated expression of a diverse set of genes during thymocyte positive selection in vivo. J. Immunol. 2004; 173:5434-5444. [PubMed: 15494490]

3. Ueno T, et al. CCR7 signals are essential for cortex-medulla migration of developing thymocytes. J. Exp. Med. 2004; 200:493-505. [PubMed: 15302902]

4. Setoguchi R, et al. Repression of the transcription factor Th-POK by Runx complexes in cytotoxic $\mathrm{T}$ cell development. Science. 2008; 319:822-825. [PubMed: 18258917]

5. He X, et al. CD4-CD8 lineage commitment is regulated by a silencer element at the ThPOK transcription-factor locus. Immunity. 2008; 28:346-358. [PubMed: 18342007]

6. Kishimoto H, Sprent J. Negative selection in the thymus includes semimature T cells. J. Exp. Med. 1997; 185:263-271. [PubMed: 9016875]

7. Villunger A, et al. Negative selection of semimature $\mathrm{CD}^{+} 8^{-} \mathrm{HSA}^{+}$thymocytes requires the BH3only protein Bim but is independent of death receptor signaling. Proc. Natl. Acad. Sci. USA. 2004; 101:7052-7057. [PubMed: 15118096]

8. Cowan JE, et al. The thymic medulla is required for Foxp3+ regulatory but not conventional CD4+ thymocyte development. J Exp Med. 2013; 210:675-681. [PubMed: 23530124]

9. Li J, et al. Developmental pathway of CD4+CD8- medullary thymocytes during mouse ontogeny and its defect in Aire-/- mice. Proc. Natl. Acad. Sci. USA. 2007; 104:18175-18180. [PubMed: 17984055]

10. McCaughtry TM, Wilken MS, Hogquist KA. Thymic emigration revisited. J. Exp. Med. 2007; 204:2513-2520. [PubMed: 17908937]

11. Cowan JE, et al. Differential requirement for CCR4 and CCR7 during the development of innate and adaptive aßT cells in the adult thymus. J. Immunol. 2014; 193:1204-1212. [PubMed: 24990081]

12. Boursalian TE, Golob J, Soper DM, Cooper CJ, Fink PJ. Continued maturation of thymic emigrants in the periphery. Nat. Immunol. 2004; 5:418-425. [PubMed: 14991052]

13. Mingueneau $\mathrm{M}$, et al. The transcriptional landscape of $\alpha \beta \mathrm{T}$ cell differentiation. Nat Immunol. 2013; 14:619-632. [PubMed: 23644507]

14. Singer A, Adoro S, Park JH. Lineage fate and intense debate: myths, models and mechanisms of CD4- versus CD8-lineage choice. Nat. Rev. Immunol. 2008; 8:788-801. [PubMed: 18802443]

15. Matloubian M, et al. Lymphocyte egress from thymus and peripheral lymphoid organs is dependent on S1P receptor 1. Nature. 2004; 427:355-360. [PubMed: 14737169]

16. Arbonés ML, et al. Lymphocyte homing and leukocyte rolling and migration are impaired in Lselectin-deficient mice. Immunity. 1994; 1:247-260. [PubMed: 7534203]

17. Carlson CM, et al. Kruppel-like factor 2 regulates thymocyte and T-cell migration. Nature. 2006; 442:299-302. [PubMed: 16855590]

18. Priyadharshini B, Welsh RM, Greiner DL, Gerstein RM, Brehm MA. Maturation-dependent licensing of naive T cells for rapid TNF production. PLoS One. 2010; 5:e15038. [PubMed: 21124839]

19. Hoffmann R, Melchers F. A genomic view of lymphocyte development. Curr. Opin. Immunol. 2003; 15:239-245. [PubMed: 12787746]

20. Ramsdell F, Jenkins M, Dinh Q, Fowlkes BJ. The majority of CD4 ${ }^{+} 8^{-}$thymocytes are functionally immature. J. Immunol. 1991; 147:1779-1785. [PubMed: 1679836]

21. Aliahmad P, Kaye J. Commitment issues: linking positive selection signals and lineage diversification in the thymus. Immunol. Rev. 2006; 209:253-273. [PubMed: 16448547]

22. Carpenter AC, Bosselut R. Decision checkpoints in the thymus. Nat. Immunol. 2010; 11:666-673. [PubMed: 20644572]

23. Hogquist KA, Xing Y, Hsu FC, Shapiro VS. T Cell Adolescence: Maturation Events Beyond Positive Selection. J. Immunol. 2015; 195:1351-1357. [PubMed: 26254267]

24. Sato $\mathrm{S}$, et al. TAK1 is indispensable for development of T cells and prevention of colitis by the generation of regulatory T cells. Int. Immunol. 2006; 18:1405-1411. [PubMed: 16940043]

25. Kurobe H, et al. CCR7-dependent cortex-to-medulla migration of positively selected thymocytes is essential for establishing central tolerance. Immunity. 2006; 24:165-177. [PubMed: 16473829] 
26. Wan YY, Chi H, Xie M, Schneider MD, Flavell RA. The kinase TAK1 integrates antigen and cytokine receptor signaling for T cell development, survival and function. Nat. Immunol. 2006; 7:851-858. [PubMed: 16799562]

27. Liu ZG, Hsu H, Goeddel DV, Karin M. Dissection of TNF receptor 1 effector functions: JNK activation is not linked to apoptosis while NF-kappaB activation prevents cell death. Cell. 1996; 87:565-576. [PubMed: 8898208]

28. Adhikari A, Xu M, Chen ZJ. Ubiquitin-mediated activation of TAK1 and IKK. Oncogene. 2007; 26:3214-3226. [PubMed: 17496917]

29. Jimi E, Strickland I, Voll RE, Long M, Ghosh S. Differential role of the transcription factor NFkappaB in selection and survival of $\mathrm{CD}^{+}$and $\mathrm{CD}^{+}$thymocytes. Immunity. 2008; 29:523-537. [PubMed: 18957265]

30. Otero DC, Baker DP, David M. IRF7-dependent IFN- $\beta$ production in response to RANKL promotes medullary thymic epithelial cell development. J. Immunol. 2013; 190:3289-3298. [PubMed: 23440417]

31. Lienenklaus $\mathrm{S}$, et al. Novel reporter mouse reveals constitutive and inflammatory expression of IFN-beta in vivo. J. Immunol. 2009; 183:3229-3236. [PubMed: 19667093]

32. Gough DJ, et al. Functional crosstalk between type I and II interferon through the regulated expression of STAT1. PLoS Biol. 2010; 8:e1000361. [PubMed: 20436908]

33. Hata N, et al. Constitutive IFN-alpha/beta signal for efficient IFN-alpha/beta gene induction by virus. Biochem Biophys Res Commun. 2001; 285:518-525. [PubMed: 11444873]

34. Gough DJ, Messina NL, Clarke CJ, Johnstone RW, Levy DE. Constitutive type I interferon modulates homeostatic balance through tonic signaling. Immunity. 2012; 36:166-174. [PubMed: 22365663]

35. Dong J, et al. Homeostatic properties and phenotypic maturation of murine CD4+ pre-thymic emigrants in the thymus. PLoS One. 2013; 8:e56378. [PubMed: 23409179]

36. Abt MC, et al. Commensal bacteria calibrate the activation threshold of innate antiviral immunity. Immunity. 2012; 37:158-170. [PubMed: 22705104]

37. Kawashima T, et al. Double-stranded RNA of intestinal commensal but not pathogenic bacteria triggers production of protective interferon- $\beta$. Immunity. 2013; 38:1187-1197. [PubMed: 23791646]

38. Ganal SC, et al. Priming of natural killer cells by nonmucosal mononuclear phagocytes requires instructive signals from commensal microbiota. Immunity. 2012; 37:171-186. [PubMed: 22749822]

39. Yu Q, et al. DNA-damage-induced type I interferon promotes senescence and inhibits stem cell function. Cell Rep. 2015; 11:785-797. [PubMed: 25921537]

40. Härtlova A, et al. DNA damage primes the type I interferon system via the cytosolic DNA sensor STING to promote anti-microbial innate immunity. Immunity. 2015; 42:332-343. [PubMed: 25692705]

41. Metidji A, et al. IFN- $\alpha / \beta$ receptor signaling promotes regulatory T cell development and function under stress conditions. J. Immunol. 2015; 194:4265-4276. [PubMed: 25795758]

42. Silke J. The regulation of TNF signalling: what a tangled web we weave. Curr. Opin. Immunol. 2011; 23:620-626. [PubMed: 21920725]

43. Zhang N, He YW. An essential role for c-FLIP in the efficient development of mature T lymphocytes. J. Exp. Med. 2005; 202:395-404. [PubMed: 16043517]

44. Jost PJ, et al. Bcl10/Malt1 signaling is essential for TCR-induced NF-kappaB activation in thymocytes but dispensable for positive or negative selection. J. Immunol. 2007; 178:953-960. [PubMed: 17202357]

45. Molinero LL, et al. CARMA1 controls an early checkpoint in the thymic development of FoxP3+ regulatory T cells. J. Immunol. 2009; 182:6736-6743. [PubMed: 19454668]

46. Barnes MJ, et al. Commitment to the regulatory T cell lineage requires CARMA1 in the thymus but not in the periphery. PLoS Biol. 2009; 7:e51. [PubMed: 19260764]

47. Sinclair C, Seddon B. Overlapping and asymmetric functions of TCR signaling during thymic selection of CD4 and CD8 lineages. J. Immunol. 2014; 192:5151-5159. [PubMed: 24771853] 
48. Chen W, Konkel JE. Development of thymic Foxp3(+) regulatory T cells: TGF- $\beta$ matters. Eur. J. Immunol. 2015; 45:958-965. [PubMed: 25684698]

49. Rubtsov YP, Rudensky AY. TGFbeta signalling in control of T-cell-mediated self-reactivity. Nat. Rev. Immunol. 2007; 7:443-453. [PubMed: 17525753]

50. Mahmud SA, et al. Costimulation via the tumor-necrosis factor receptor superfamily couples TCR signal strength to the thymic differentiation of regulatory T cells. Nat. Immunol. 2014; 15:473481. [PubMed: 24633226]

51. Weinreich MA, et al. KLF2 transcription-factor deficiency in T cells results in unrestrained cytokine production and upregulation of bystander chemokine receptors. Immunity. 2009; 31:122130. [PubMed: 19592277]

52. Subramanian A, et al. Gene set enrichment analysis: a knowledge-based approach for interpreting genome-wide expression profiles. Proc. Natl. Acad. Sci. USA. 2005; 102:15545-15550. [PubMed: 16199517]

53. Mootha VK, et al. PGC-1alpha-responsive genes involved in oxidative phosphorylation are coordinately downregulated in human diabetes. Nat. Genet. 2003; 34:267-273. [PubMed: 12808457] 


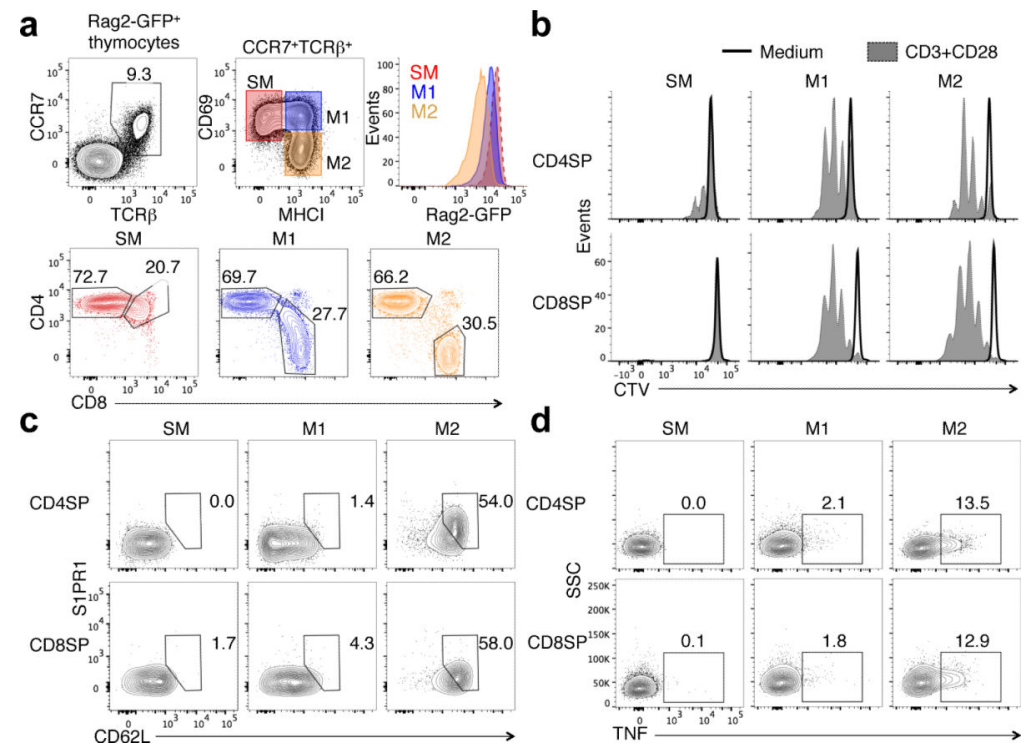

Figure 1. Three major SP stages defined by function

(a) Flow cytometry of thymocytes from $R A G 2^{\mathrm{GFP}}$ transgenic mice ( $n=4$ mice). In the upper row, the left panel shows the expression of CCR7 and TCR $\beta$ by Rag2-GFP ${ }^{+}$thymocytes dump-gated as Supplemetary Fig. 1a; the middle panel shows the gates of three subsets of medullary thymocytes identified by expression of CD69 and MHCI; the right panel shows GFP expression level by histogram overlay of $\mathrm{CD} 69^{+} \mathrm{MHCI}^{-}$or semi-mature (SM), $\mathrm{CD}{ }^{+} \mathrm{MHCI}^{+}$or mature 1 (M1) and $\mathrm{CD}^{-} 9^{-} \mathrm{MHCI}^{+}$or mature 2 (M2) cells. The lower row of panels shows CD4 and CD8 expression profiles of these three indicated populations. Representative contour plots and histogram are shown among four different experiments. (b) CellTrace Violet cell proliferation analysis of CD4SP and CD8SP subsets by flow cytometry. SM, M1 and M2 subsets of CD4SP thymocytes were sorted from C57BL/6 mice; CD8SP subsets were sorted from MHC class II-deficient mice. Cells were stimulated with anti-CD3 and anti-CD28 for 3 days. Representative histograms are shown among three different experiments.

(c) S1PR1 and CD62L expression on the subsets of CD4SP and CD8SP thymocytes. Representative contour plots are shown among three different experiments.

(d) TNF production in CD4SP or CD8SP thymocytes 4 hours after anti-CD3 and anti-CD28 stimulation. Representative plots are shown among three different experiments. Numbers indicate frequency of cells in adjacent gates. 

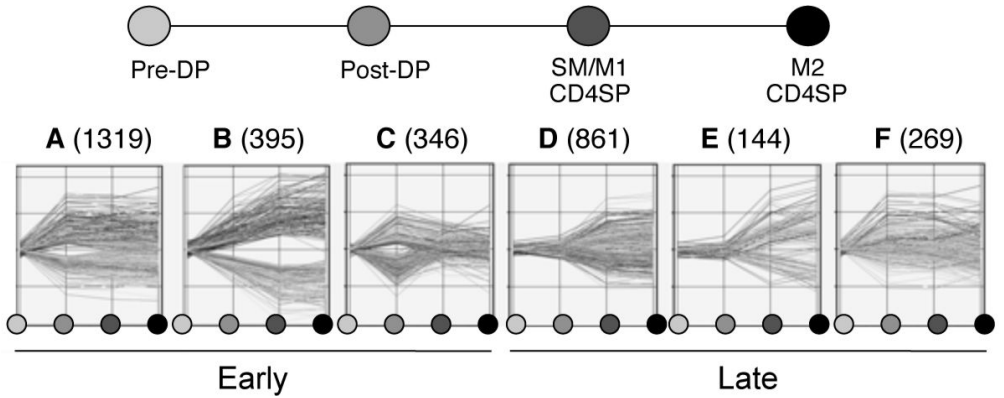

Figure 2. Transcriptome analysis of late stages of thymocytes

Microarray data were obtained from triplicate preparations of sorted Pre-DP, Post-DP, $\mathrm{Qa}^{2}{ }^{-} \mathrm{CD} 69^{+}(\mathrm{SM} / \mathrm{M} 1)$ and $\mathrm{Qa}^{+}{ }^{+} \mathrm{CD} 69^{-}$(M2) CD4SP thymocytes, and were analyzed using GeneSpring software. Gene changes were categorized by six patterns of change among the four populations (indicated A-F) using Venn Diagram and Profile Plot operations. The number of genes in each pattern group is indicated. "Early" and "Late" represent categories of genes changed as indicated. 


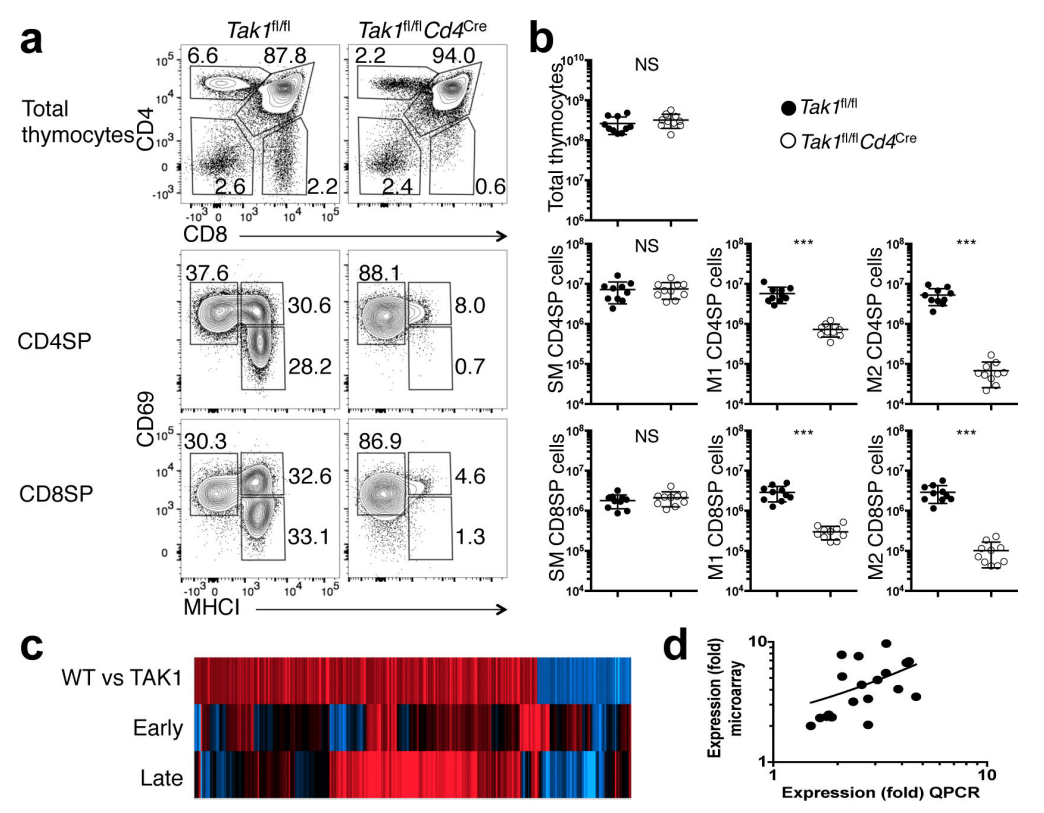

Figure 3. TAK1 is required for SM to M1

(a) Flow cytometry analysis of thymocytes from $\operatorname{Ta}_{k} I^{\mathrm{fl} / \mathrm{fl}}$ (control) or $\mathrm{Ta} k I^{\mathrm{fl} / \mathrm{fl}} \mathrm{Cd} \mathrm{C}^{\mathrm{Cre}}$ (TAK1-deficient) mice. Upper panels show CD4 and CD8 expression profiles of total thymocytes; Lower two rows of panels show proportions of SM, M1 and M2 in CD4SP or CD8SP lineage cells (excluding CD1d/aGalCer ${ }^{+} \mathrm{NKT}, \mathrm{CD} 25^{+} \mathrm{T}_{\text {reg }}, \mathrm{CD} 44^{\text {hi }}$ recirculating memory, and $\mathrm{GL}^{+} \gamma \delta \mathrm{T}$ cells). Representative contour plots are shown among nine independent experiments. Numbers indicate frequency of cells in adjacent gates.

(b) Cell numbers of total thymocytes or indicated populations of TAK1-deficient $(n=10)$ or control mice $(n=10)$. Pooled data from nine independent experiments are shown. Each symbol represents a single mouse; horizontal bars represent group mean values \pm s.d.; NS, not significant; $* P \leq 0.05, * * P \leq 0.01, * * * P \leq 0.001$, two-tailed unpaired Student's $t$-test.

(c) Microarray analysis was performed on triplicate preparations of sorted SM/M1 CD4SP thymocytes from $\operatorname{Ta} k I^{\mathrm{fl} / \mathrm{fl}}$ versus $\operatorname{Tak}^{\mathrm{fl} / \mathrm{fl}} C d 4^{\text {Cre }}$ mice. Heat map shows 381 genes differentially expressed between these $(P \leq 0.05$ and fold change $\geq 2.0$.) Red indicates upregulated genes and blue indicates downregulated genes. "Early" and "Late" represent the two categories of genes changed as described in Fig. 2.

(d) The expression levels of select TAK1-dependent genes from microarray analysis were confirmed by qPCR analysis using separately sorted SM/M1 cells from Tak $I^{\mathrm{fl} / \mathrm{fl}}$ and $T a k I^{\mathrm{fl} / \mathrm{fl}} C d 4^{\mathrm{Cre}}$ mice. Mean values are shown from three independent experiments. Pearson correlation coefficient $r=0.46, P<0.05$ (two tailed). 


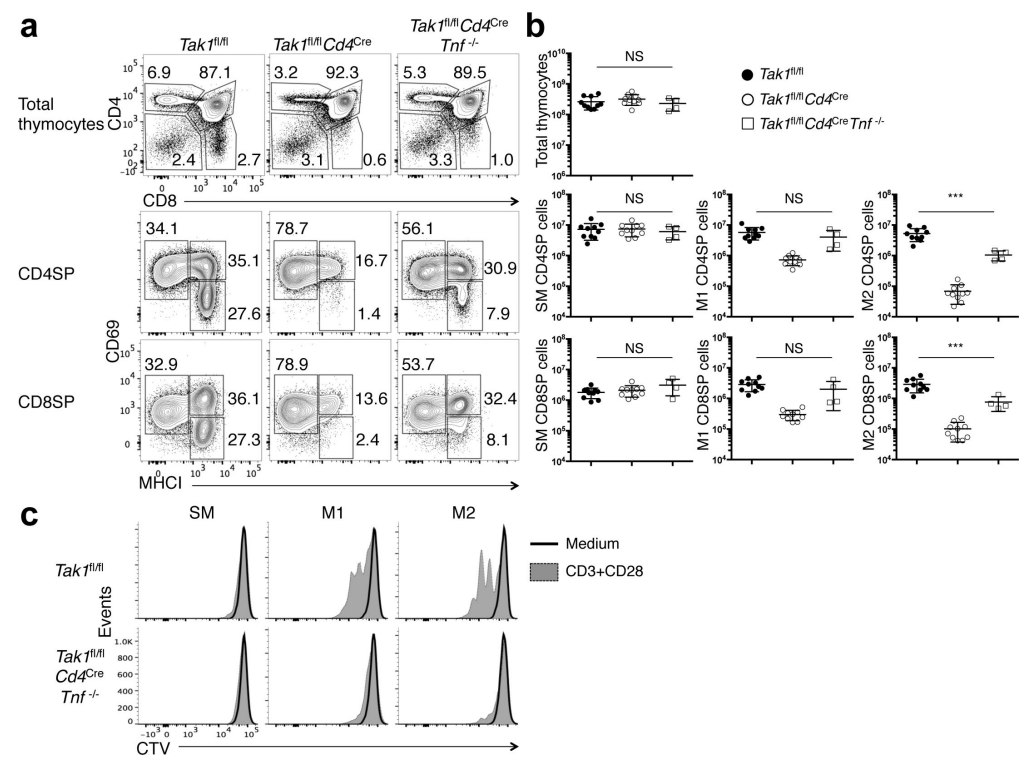

Figure 4. TNF blockade activity restored maturation but not proliferation

(a) Flow cytometry analysis of thymocytes from $\mathrm{Tak}^{\mathrm{fl} / \mathrm{fl}} \mathrm{Cd}^{\mathrm{Cre}} \mathrm{Tnf}^{-1-}$ mice or controls. Upper panels show CD4 and CD8 profiles; Lower two rows of panels show proportions of SM, M1 and M2 in CD4SP or CD8SP cells (excluding NKT, Treg, recirculating memory, and $\gamma \delta$ T cells). Representative data from four independent experiments are shown. Numbers indicate frequency of cells in adjacent gates.

(b) Cell numbers of total thymocytes or indicated populations from Tak $\mathrm{f}^{\mathrm{f} / \mathrm{fl}}(\mathrm{n}=10)$, $T a k I^{\mathrm{fl} / \mathrm{fl}} C d 4^{\mathrm{Cre}}(\mathrm{n}=10)$ or $T a k I^{\mathrm{fl} / \mathrm{fl}} C d 4^{\mathrm{Cre}} \operatorname{Tnf}^{/-}$mice $(\mathrm{n}=4)$. Each symbol represents a single mouse; horizontal bars represent group mean values \pm s.d.; NS, not significant; $* P \leq 0.05$, $* * P \leq 0.01, * * * P \leq 0.001$, two-tailed unpaired Student's $t$-test.

(c) CellTrace Violet cell proliferation analysis of sorted SM, M1 and M2 CD4SP thymocytes from the indicated mice in response to anti-CD3 plus anti-CD28 stimuli after 3 days of culture. Representative data from two independent experiments are shown. 


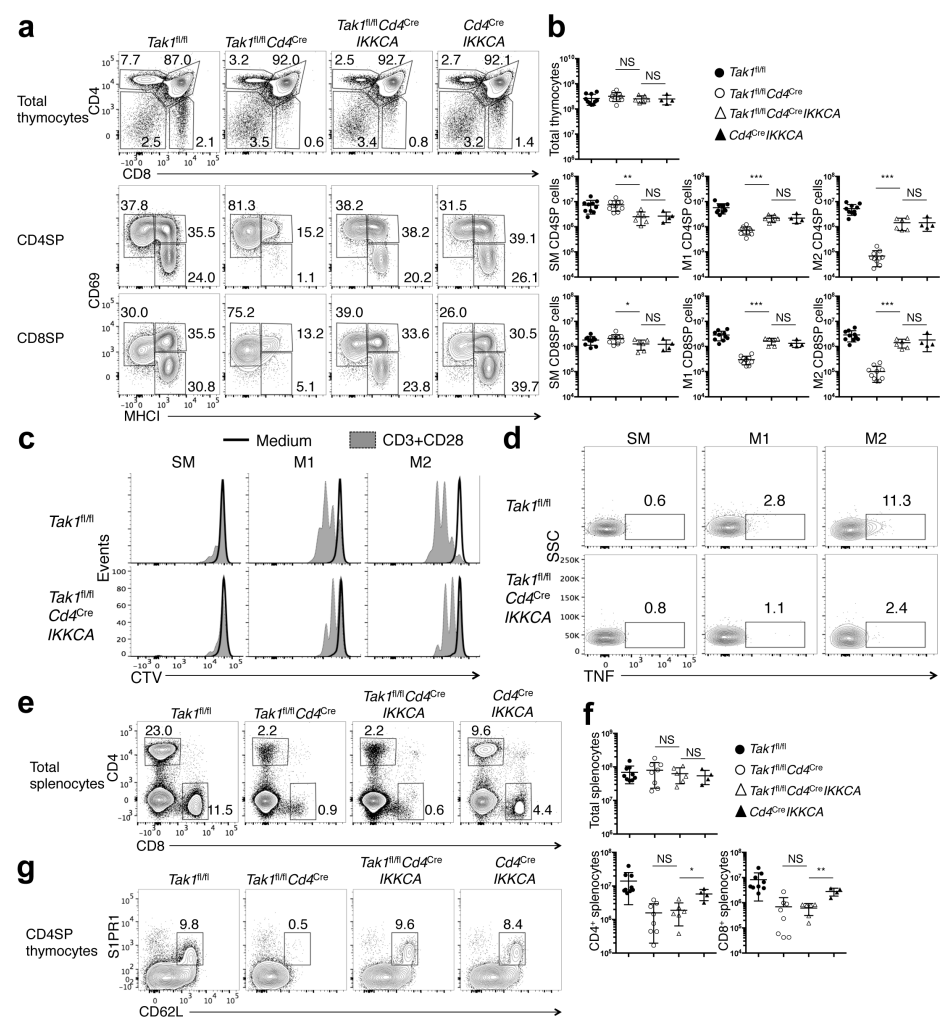

Figure 5. IKK activity restored proliferation and maturation but not licensing and survival (a) Flow cytometry analysis of thymocytes from $T a k I^{\mathrm{fl} / \mathrm{fl}} C d 4^{\mathrm{Cre}} I K K C A$ mice or controls. Lower two rows of panels show proportions of SM, M1 and M2 in CD4SP or CD8SP cells (excluding NKT, Treg, recirculating memory, and $\gamma \delta$ T cells). Representative data from four independent experiments are shown. Numbers indicate frequency of cells in adjacent gates.

(b) Cell numbers of total thymocytes or indicated populations from Tak $I^{\mathrm{fl} / \mathrm{fl}}(n=10)$, $T a k I^{\mathrm{fl} / \mathrm{fl}} C d 4^{\mathrm{Cre}}(n=10), T a k I^{\mathrm{fl} / \mathrm{fl}} C d 4^{\mathrm{Cre}} I K K C A(n=6)$ or $C d 4^{\text {Cre }} I K K C A$ mice $(n=4)$. Each symbol represents a single mouse; horizontal bars represent group mean values \pm s.d.; NS, not significant; $* P \leq 0.05, * * P \leq 0.01, * * * P \leq 0.001$, two-tailed unpaired Student's $t$-test. (c) CellTrace Violet cell proliferation analysis of sorted SM, M1 and M2 CD4SP thymocytes from the indicated mice in response to anti-CD3/28 stimuli after 3 days of culture.

Representative data from three independent experiments are shown.

(d) TNF production in SM, M1 and M2 CD4SP cells stimulated by anti-CD3/28 for 4 hours. Representative data from three independent experiments are shown. Numbers indicate frequency of cells in adjacent gates.

(e) Flow cytometry analyzing $\mathrm{CD}^{+}$and $\mathrm{CD}^{+} \mathrm{T}$ cells in splenocytes from $T a k I^{\mathrm{fl} / \mathrm{fl}} C d 4^{\mathrm{Cre}} I K K C A$ mice or controls. Representative data from four independent experiments are shown. Numbers indicate frequency of cells in adjacent.

(f) Cell numbers of total splenocytes, CD4 or CD8 T cells in the spleens from Tak $I^{\mathrm{fl} / \mathrm{fl}}$ $(\mathrm{n}=9), \operatorname{Ta} k I^{\mathrm{fl} / \mathrm{fl}} C d 4^{\mathrm{Cre}}(n=8), \operatorname{Ta} I^{\mathrm{fl} / \mathrm{fl}} C d 4^{\mathrm{Cre}} I K K C A(n=6)$ or $C d 4^{\text {Cre }} I K K C A$ mice $(n=4)$.

Each symbol represents a single mouse; horizontal bars represent group mean values \pm s.d.; NS, not significant; $* P \leq 0.05, * * P \leq 0.01$, ***P $\leq 0.001$, two-tailed unpaired Student's $t$ test. 
(g) Flow cytometry profile of CD4SP thymocytes from indicated mice. Representative data from four independent experiments are shown. Numbers indicated frequency of cells in adjacent gates. 
a

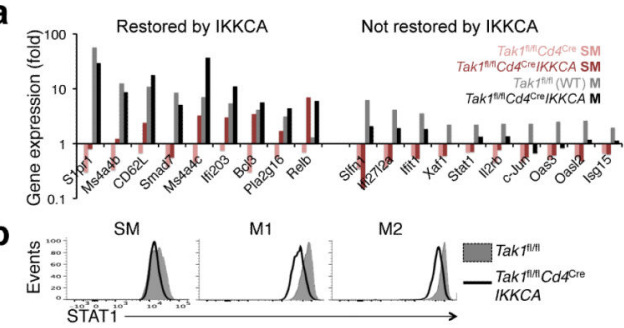

C

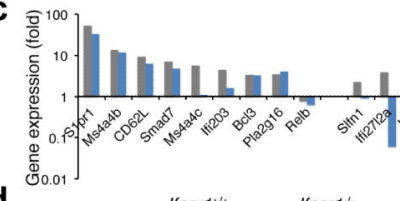

d

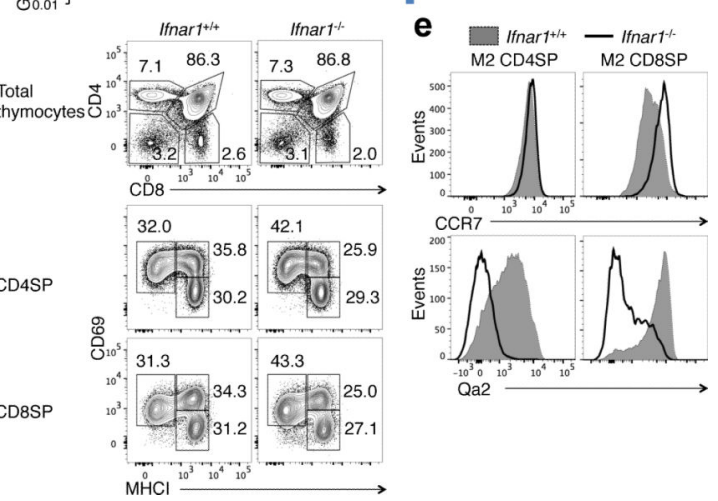

Figure 6. IFN-regulated genes and STAT1 levels are not rescued by IKKCA and IFNaR required for Qa2 expression, but not maturation

(a) Quantification of mRNA expression of select TAK1-dependent genes in sorted CD24 ${ }^{\text {hi }} \mathrm{CD}_{62} \mathrm{~L}^{\text {lo }}(\mathrm{SM})$ or CD24 ${ }^{\text {int }} \mathrm{CD} 62 \mathrm{~L}^{\text {hi }}(\mathrm{M}) \mathrm{CD} 4 \mathrm{SP}$ thymocytes from $\operatorname{Tak}^{\mathrm{fl} / \mathrm{fl}}(n=2)$, $T a k 1^{\mathrm{fl} / \mathrm{fl}} C d 4^{\mathrm{Cre}}(n=2)$ or $T a k 1^{\mathrm{fl} / \mathrm{fl}} C d 4^{\mathrm{Cre}} I K K C A(n=2)$ mice, as indicated. The gene expression levels (fold) are relative to those in $T_{a k} I^{\mathrm{fl} / \mathrm{fl}} \mathrm{SM}$ cells. Genes are arranged on the graph by those whose expression was restored to control levels by the IKKCA transgene (left) or not (right).

(b) STAT1 protein expression in subsets of CD4SP thymoctyes from Tak $1^{\mathrm{fl} / \mathrm{fl}} C d 4^{\mathrm{Cre}} I K K C A$ mice or controls. Representative data from two independent experiments are shown.

(c) Quantification of mRNA expression of the same select TAK1-dependent genes as those in (a) in sorted CD24 ${ }^{\text {int }}$ CD62L ${ }^{\text {hi }}(\mathrm{M})$ CD4SP thymocytes from WT $(n=3)$ or Ifnar $^{-1-}(n=3)$ mice as indicated.

(d) Flow cytometry analysis of thymocytes from Ifnar $1^{-/-}$mice or controls. Upper panels show CD4 and CD8 profiles; Lower two rows of panels show proportions of SM, M1 and M2 in CD4SP or CD8SP cells (excluding NKT, Treg, recirculating memory, and $\gamma \delta$ T cells). Representative data from three independent experiments are shown. Numbers indicate frequency of cells in adjacent gates.

(e) CCR7 and Qa2 expression on M2 CD4SP thymocytes in Ifnar $1^{-1-}$ mice or controls ( $n=3$ per group). Representative data from three independent experiments are shown. 


\section{Table 1}

Gene set enrichment analysis (GSEA) of microarray data showing enrichment of gene sets that share a conserved transcription factor binding motif in the promoters and 3'UTRs of genes that changed between the stages noted.

\begin{tabular}{|ccccccccc|}
\hline \multicolumn{3}{|c}{ PreDP to PostDP } & \multicolumn{2}{c|}{ PostDP to SM/M1 } & \multicolumn{2}{c|}{ SM/M1 to M2 } \\
\hline Name & $\#$ & NES & Name & $\#$ & NES & Name & $\#$ & NES \\
\hline ATF & 3 & 1.97 & E2F & 14 & 1.84 & NONE & $\geq 1.60$ \\
EGR & 6 & 1.86 & NF-kb & 1 & 1.62 & NONE & $\leq-1.60$ \\
CREB1 & 3 & 1.83 & IRF & 1 & 1.62 & & \\
E4F1 & 1 & 1.82 & ATF & 1 & -1.60 & & \\
NF-kb & 4 & 1.78 & EGR & 2 & -1.73 & & \\
ETS & 3 & 1.73 & PAX8 & 1 & -1.62 & & \\
ELK1 & 1 & 1.71 & NFAT & 1 & -1.60 & & \\
SRF & 2 & 1.70 & & & & & \\
PU.1 & 1 & 1.65 & & & & & \\
STAT1 & 1 & 1.62 & & & & & \\
NERF & 1 & 1.61 & & & & & \\
E2F & 8 & -1.62 & & & & & \\
\hline
\end{tabular}

Only gene sets with normalized enrichment scores (NES) $\geq 1.6$ or $\leq-1.6$ are shown. Bold font indicates upregulated gene sets; non-bold font indicates downregulated gene sets.

\# refers to the number of gene sets related to that transcription factor that were enriched. 